NBER WORKING PAPER SERIES

REGULATION AND INVESTMENT

\author{
Alberto Alesina \\ Silvia Ardagna \\ Giuseppe Nicoletti \\ Fabio Schiantarelli \\ Working Paper 9560 \\ http://www.nber.org/papers/w9560
}
NATIONAL BUREAU OF ECONOMIC RESEARCH
1050 Massachusetts Avenue
Cambridge, MA 02138
March 2003

We would like to thank Frank Gollop and participants at seminars at Boston College, Brandeis and IGIER Bocconi for useful comments. Alesina is grateful for financial support to the NSF for a grant through the NBER. The views expressed in the paper are those of the authors and do not necessarily represent those of the institutions to which they are affiliated or the National Bureau of Economic Research.

(C2003 by Alberto Alesina, Silvia Ardagna, Giuseppe Nicoletti, and Fabio Schiantarelli. All rights reserved. Short sections of text not to exceed two paragraphs, may be quoted without explicit permission provided that full credit including Cnotice, is given to the source. 
Regulation and Investment

Alberto Alesina, Silvia Ardagna, Giuseppe Nicoletti, and Fabio Schiantarelli

NBER Working Paper No. 9560

March 2003

JEL No. A1

\section{ABSTRACT}

One commonly held view about the difference between continental European countries and other OECD economies, especially the United States, is that the heavy regulation of Europe reduces its growth. Using newly assembled data on regulation in several sectors of many OECD countries, we provide substantial and robust evidence that various measures of regulation in the product market, concerning in particular entry barriers, are negatively related to investment. The implications of our analysis are clear: regulatory reforms, especially those that liberalize entry, are very likely to spur investment.

Alberto Alesina

Department of Economics

Harvard University

Cambridge, MA 02138

and NBER

aalesina@harvard.edu

Giuseppe Nicoletti

OECD
Silvia Ardagna

Wellesley College

Fabio Schiantarelli

Boston College 


\title{
Regulation and Investment
}

\author{
Alberto Alesina, Silvia Ardagna, Giuseppe Nicoletti, and Fabio Schiantarelli* \\ (Harvard University, Wellesley College, OECD, and Boston College)
}

December 2002

Revised February 2003

\begin{abstract}
One commonly held view about the difference between continental European countries and other OECD economies, especially the United States, is that the heavy regulation of Europe reduces its growth. Using newly assembled data on regulation in several sectors of many OECD countries, we provide substantial and robust evidence that various measures of regulation in the product market, concerning in particular entry barriers, are negatively related to investment. The implications of our analysis are clear: regulatory reforms, especially those that liberalize entry, are very likely to spur investment.
\end{abstract}

\section{Introduction}

In the past decade the rate of GDP growth has been remarkably different amongst OECD countries. One of the most striking and often cited comparison is the one between the US with a 4.3 percent average GDP growth in the second half of the nineties and large continental European economies (Germany, Italy and France) with 2 percent average growth. One commonly held explanation of these differences is that a stricter regulation of markets has prevented faster growth in many European countries especially in a period, the nineties, of rapid technological innovation. Is this true? This paper suggests that the answer is "yes": various measures of product market regulation are negatively related to investment, which is, of course, an important engine of growth.

\footnotetext{
*We would like to thank Frank Gollop and participants at seminars at Boston College, Brandeis and IGIER Bocconi for useful comments. Alesina is grateful for financial support to the NSF for a grant through the NBER. The views expressed in the paper are those of the authors and do not necessarily represent those of the institutions to which they are affiliated.
} 
In the last decade or so, most OECD countries have experienced some form of regulatory reforms (deregulation for short) implying entry liberalization and privatization. However, the timing, extent, nature, and starting point varies across countries. For instance, the United States started deregulating earlier, already in the seventies. In 1977, 17 per cent of the US GNP was produced by fully regulated industries, and by 1988 this total had been cut to 6.6 percent of GNP. ${ }^{1}$ Other early and decisive reformers have been New Zealand and Britain, while laggards have been Italy and France.

We rely on these diverse histories to study the effects of regulatory reforms in sectors which were traditionally most heavily sheltered from competition and have witnessed, at different times and to different degrees, some form of deregulation and privatization in various countries. Specifically, we look at the effects of regulation on investment in the transport (airlines, road freight and railways), communication (telecommunications and postal) and utilities (electricity and gas) sectors. We measure regulation with different time varying indicators that capture entry barriers and the extent of public ownership, among other things.

We find that regulatory reforms have had a significant positive impact on capital accumulation in the transport, communication, and utilities industries. In particular, liberalization of entry in potentially competitive markets seems to have had the largest and most significant impact on private investment. ${ }^{2}$ The effect of privatization is less clear-cut. On the one hand privatization may lead to more profit opportunities for private firms; on the other hand public enterprises may overinvest if they pursue political objectives and/or if managers are not constrained by the discipline imposed by capital markets. There is also evidence that the marginal effect of deregulation on investment is greater when the policy reform is large and when changes occur starting from already lower levels of regulation. In other words, small changes in a heavy regulated environment are not likely to produce much of an effect.

Much of the literature on the effects of regulation in OECD countries is concerned with the labor market, see for instance, Blanchard and Wolfers (2000). Work on the macroeconomic effects of goods market is more limited. ${ }^{3}$ Blanchard and Giavazzi (2001) develop an insightful model of both labor market and product

\footnotetext{
${ }^{1}$ See Winston (1993). The figures are from the January 1991 Survey of Current Business.

${ }^{2}$ Our conclusion that less intrusive government intervention favors private investment is consistent with the finding by Alesina et al. (2002). They show in a panel of OECD countries that a reduction of the size of government measured by total spending over GDP and total taxation increases the private accumulation of capital. Results by Blanchard and Perotti (2002) specifically on the US are on the same line.

${ }^{3}$ There is of course a vast literature on the microeconomics of regulation and deregulation. See for instance the survey by Joskow and Rose (1989) and Winston (1993).
} 
market regulation and their interconnection. Nicoletti et al. (2001a, b) provide empirical evidence in favor of a negative effect of anti-competitive product market regulation on employment in a panel of OECD countries. Moreover, Nicoletti and Scarpetta (2002) find that product market regulation lowers multifactor productivity growth in OECD countries, while Bassanini and Ernst (2002) find a negative effect of regulation on R\&D. Finally, Djankov, La Porta, Lopez de Silanes, and Shleifer (2002) focus on regulations that affect how easy it is to start a business in 85 countries. Their paper contrasts developing countries with developed ones and lends support to the view of excessive regulation as a hindrance to entrepreneurship. ${ }^{4}$ To our knowledge, there are no contributions in the literature that use broad time varying measures of product market regulation and look at the relationship between regulatory reforms and investment in a panel context.

The paper is organized as follows. Section 2 presents a simple model to illustrate the channels through which regulation can affect capital accumulation. Section 3 describes our data and, in particular, the measurement of the regulatory environment. Section 4 discusses our results in sectors (utilities, telecommunication, transport) which were heavily regulated and have experienced various forms of deregulation. The last section concludes.

\section{Product Market Regulation and Investment: Some The- ory}

Product market regulation can influence investment in several ways. First, as Blanchard and Giavazzi (2001) emphasize in a non-competitive model of employment determination, changes in regulation affect the markup of prices over marginal costs, because of their impact, for instance, on entry barriers and, hence, on the number of firms. Second, regulation can influence the costs that even existing firms face when expanding their productive capacity. For example, red tape and other forms of regulatory burdens can increase firms' costs of adjusting the capital stock and hamper their capacity to react to changes in fundamentals. Third, for certain sectors, regulation imposes a ceiling on the rate of return on capital that firms are allowed to earn; this affects the demand for capital relative to labor (Averch and Johnson (1962)). Finally, if product markets regulatory reforms occur together with privatization (or nationalization) policies, changes in ownership structure can also affect investment.

\footnotetext{
${ }^{4}$ A related literature asks the question whether competition stimulates firms' productivity. See, for instance, Nickell (1996) who shows that both the level and growth rates of firms' productivity are positively affected by measures of competition. This suggests that regulatory reforms should have positive productivity effects, insofar as they succeed in stimulating competition.
} 
We begin by embedding the first two ideas in a standard model of investment with imperfect competition in the output market. ${ }^{5}$ We then discuss the effect of regulation that imposes a ceiling on the rate of return on capital and the effect of a reduction in the importance of public enterprises.

\subsection{Regulation, the markup and adjustment costs}

We assume that each monopolistic competitive firm produces a differentiated product with capital and labor and faces a demand for its good of the form:

$$
\frac{Y_{i}}{\bar{Y}}=D\left(\frac{P_{i}}{\bar{P}}\right)=\left(\frac{P_{i}}{\bar{P}}\right)^{-\varepsilon}
$$

where $\bar{Y}$ is average real output demanded, $\bar{P}$ the average price level, and $\varepsilon$ the elasticity of demand. ${ }^{6}$ As in Blanchard and Giavazzi (2001), we assume that the elasticity of demand varies inversely with the degree of product market regulation: tighter regulation is associated with a lower elasticity. One way to rationalize this is to assume that the elasticity of demand is an increasing function of the number of firms, $m$. Hence, $\varepsilon=g(m)$, where $g^{\prime}(\cdot)>0 .^{7}$ If we define the markup of prices

over marginal costs as $(1+\mu)=\left(\frac{1}{1-\frac{1}{\varepsilon}}\right)$, then $\mu$ is a decreasing function of the number of firms $\left(\mu=\mu(g(m))\right.$, with $\left.\mu^{\prime}<0\right)$.

We begin by assuming that the regulatory authority (the government for short) determines administratively the number of firms. In this case, deregulation of product markets leads to a larger number of firms, hence, a decrease in $\mu$. In the next section, we let instead the number of firms to be endogenously determined by a standard entry condition, but entry is costly and regulation determines the size of

\footnotetext{
${ }^{5}$ In Blanchard and Giavazzi (2001) output is a function of employment only. The focus of this paper is on product and labor market regulation. We abstract from non-competitive labor markets and from labor market regulation, but we endogeneize the capital stock. See also Spector (2002).

${ }^{6}$ If the demand functions are derived from Dixit-Stiglitz preferences, $\bar{P}$ has the standard CES form.

${ }^{7}$ Other aspects of regulation may also affect the elasticity of demand, for any given $m$. For instance, changes in tariff and non tariff barriers may affect the availability of foreign products on domestic markets and, hence, the elasticity of demand. Similarly, the latter will be affected by the introduction of common standards across countries. A simple way to modify the model to account for such effects would be to write, as Blanchard and Giavazzi (2001) do, $\varepsilon=\bar{\varepsilon} g(m)$, where $g^{\prime}(\cdot)>0$ and $\bar{\varepsilon}$ captures the aspects of product market regulation mentioned above. Since we do not focus on changes in trade barriers or on the introduction of common standards, we will continue with our simpler specification. Finally, note also that an inverse relation between the markup and the number of firms can be obtained in a variety of models and does not require a model with product differentiation. For instance, it holds in a model with Cournot competition and homogenoeous products.
} 
such costs. Firms choose capital and labor to maximize the present discounted value of cash flow $V$ :

$$
V=\int_{0}^{\infty} e^{-r t}\left[\frac{P_{i}}{\bar{P}} F\left(K_{i}, L_{i}\right)-\frac{W}{\bar{P}} L_{i}-I_{i}-\frac{b}{2}\left(\frac{I_{i}}{K_{i}}\right)^{2} K_{i}\right] d t
$$

where $K_{i}, L_{i}$, and $I_{i}$ denote capital, labor and investment, respectively. $F\left(K_{i}, L_{i}\right)$ is linear and homogeneous in $K_{i}$ and $L_{i}$ with decreasing returns to each factor, $W$ is the nominal wage (assumed to be identical for each firm) and $r$ is the real rate of interest. $^{8}$

Firms face adjustment costs that have the standard linear homogeneous quadratic form $\frac{b}{2}\left(\frac{I_{i}}{K_{i}}\right)^{2} K_{i}$. We assume that product market regulation also affects $b$; in particular, deregulation decreases it. With this we capture the reduction in the shadow and actual costs "of doing business" associated with red tape and other administrative impediments that hamper firms' choices. The maximization problem is subject to the goods' demand function (1) and to the capital accumulation equation:

$$
\dot{K}_{i}=I_{i}-\delta K_{i}
$$

For the sake of simplicity, we assume that $r$ is exogenous, as in a small open economy, and constant. ${ }^{9}$ We can then easily derive the first order conditions for labor, investment and the capital stock. Imposing the symmetric equilibrium so that $P_{i}=\bar{P}$, substituting the first order condition for investment into the first order condition for capital and in equation (3) and rearranging, we obtain:

$$
\begin{gathered}
f(k)-k f^{\prime}(k)=(1+\mu) w \\
\dot{k}=\left[\frac{1}{b}(q-1)-\delta\right] k
\end{gathered}
$$

\footnotetext{
${ }^{8}$ Note that we are assuming constant return to scale. Some industries may be regulated because they display natural monopoly characteristics due to the presence of increasing returns. We can easily model increasing returns following Rotemberg and Woodford (1995) by using the production function $F\left(K_{i}, L_{i}\right)-\Phi$ with $F\left(K_{i}, L_{i}\right)$ displaying constant returns, and $\Phi$ representing a positive constant determined by technology only and capturing fixed costs. Note that since the first order conditions and the equations of motion remain unaltered the conclusions obtained in section 2.1 would be unchanged.

${ }^{9}$ Note that many of our countries are indeed small open economies. Another way of closing the model is to consider explicitly the consumption choice of individuals, as in Abel and Blanchard (1983). This complicates the model, without providing additional insights for the purpose at hand.
} 


$$
\dot{q}=(r+\delta) q-\left[(1+\mu)^{-1} f^{\prime}(k)+\frac{1}{2 b}(q-1)^{2}\right]
$$

where $k_{i}=K_{i} / L_{i}, w=W / \bar{P}$ and we have dropped subscript $i$ since all firms behave identically in equilibrium. Equations (5) and (6) determine the equilibrium path for the capital-labor ratio, $k$, and the shadow value of capital, $q$, for a given $\mu$ and $b$. Also, given the assumption of a fixed labor supply, $\bar{L}$, equations (5) and (6) determine the equilibrium level of the aggregate capital stock as $K=k \bar{L}$. The system is saddle-path stable. Using (5) and (6), we obtain the steady state value of $k$ as:

$$
f^{\prime}(k)=(1+\mu)\left[(r+\delta)+b \delta\left(r+\frac{\delta}{2}\right)\right]
$$

Equation (7) implies that an unanticipated permanent increase in the number of firms allowed to operate generates a decrease in the markup, $\mu$, and leads (ceteris paribus) to an increase in the steady state value of $k$ (since $f^{\prime \prime}(k)$ is negative), i.e. $\partial k / \partial m>0$. Following the decrease in $\mu$, the shadow value of capital jumps up, leading to an increase in the investment rate until the new steady state is reached. Similarly, for given $\mu$, a decrease in the adjustment cost parameter $b$ leads to an increase in the steady state level of $k$, i.e. $\partial k / \partial b>0$. In response to a regulatory reform that decreases the cost of adjusting the capital stock, the shadow value of capital initially jumps up and then it settles to a lower steady state value. Moreover, firms' investment is now more responsive to the marginal profitability of capital. Hence, the capital stock increases in the long-run.

In conclusion, deregulation, by decreasing $\mu$ or $b$ or both, leads to an expansion of the capital stock and investment through both the markup and the adjustment cost channel. Using the previous results and the first order condition of the firm with respect to labor (4), one can show that the real wage decreases in $\mu$ and $b$. A decrease in the markup or in the adjustment cost parameter leads to a higher capital stock and, hence, to a higher marginal product of labor. Moreover, the markup also acts as a tax on the use of labor, at each level of $k_{i}$. Hence, a decrease in $\mu$ leads to a higher labor demand and, given a fixed labor supply, to a higher equilibrium wage. ${ }^{10}$

\footnotetext{
${ }^{10}$ Note that in the Blanchard and Giavazzi's (2001) model, there is an inverse relationship between the real wage and the markup as well. Exogenous decreases in the markup lead to a higher real wage also in the dynamic general equilibrium model of Rotemberg and Woodford (1995) who allow for a variable labor supply and capital accumulation. Investment also increases, following a decrease in the markup.
} 


\subsection{Regulation and entry: endogenizing the number of firms}

Up to this point, we have assumed that the government can mandate the number of firms in the market. It is more realistic to assume that the number of firms is endogenously determined and can only be indirectly affected by the government through regulation of entry. Firms entry and exit the market and the number of firms is determined by the following condition:

$$
V=\int_{0}^{\infty} e^{-r t}\left[\frac{P_{i}}{\bar{P}} F\left(K_{i}, L_{i}\right)-\frac{W}{\bar{P}} L_{i}-I_{i}-\frac{b}{2}\left(\frac{I_{i}}{K_{i}}\right)^{2} K_{i}\right] d t=\bar{c} K_{i}
$$

where $\bar{c} K_{i}$ measures entry costs, established by regulation and assumed to be proportional to capital. Note that the model's qualitative conclusions on the effect of regulation on investment do not change if we assume that entry costs are proportional to labor $\left(c=\bar{c} L_{i}\right)$ or are fixed $(c=\bar{c})$. Equation (8) implies:

$$
\frac{d V}{d t}=r V-\left[\frac{P_{i}}{\bar{P}} F\left(K_{i}, L_{i}\right)-\frac{W}{\bar{P}} L_{i}-I_{i}-\frac{b}{2}\left(\frac{I_{i}}{K_{i}}\right)^{2} K_{i}\right]
$$

In steady state $I_{i}=\delta K_{i}$, and $d V / d t=0$. Hence, given the linear homogeneity of $F\left(K_{i}, L_{i}\right)$, in the symmetric equilibrium, we can rewrite the entry condition that allows to determine the number of firms $m$ as:

$$
f(k)-\frac{W}{\bar{P}}-\delta\left(1+\frac{b \delta}{2}\right) k=r \bar{c} k
$$

From the first order condition for labor (4), the wage is a function of $k$. Moreover, $k$ is an implicit function of $\mu$, hence $m$, and $b$ through (7), i.e. $k=k(\mu(g(m)), b)$, with $k_{m}>0$ and $k_{b}<0$. Therefore, (10) determines implicitly the number of firms as a function of entry costs, $c$, the adjustment cost parameter $b$, the depreciation rate $\delta$, the interest rate $r$, and the fixed labor supply, $\bar{L}$.

The effect of a change in entry costs on investment can be decomposed in: $a$ ) the impact of entry costs on the number of firms and $b$ ) the effect of the number of firms on the capital stock, i.e. $\partial k / \partial \bar{c}=(\partial k / \partial m)(\partial m / \partial \bar{c})$. We have already shown above that $\partial k / \partial m>0$, hence we need to determine the sign of $\partial m / \partial \bar{c}$. One can check that, without further assumptions, the sign of $\partial m / \partial \bar{c}$ is ambiguous. If $F\left(K_{i}, L_{i}\right)$ is Cobb-Douglas with an elasticity of output with respect to capital equal to $\alpha$, it is possible to show that a sufficient condition for deregulation to lead to an increase in the number of firms $(\partial m / \partial \bar{c}<0)$ is:

$$
\mu<\frac{1}{\alpha}-1-\frac{r+r b \delta}{r+\delta+r b \delta+\frac{b \delta^{2}}{2}}
$$


This condition is almost surely satisfied for reasonable parameters combinations, so that a decrease in entry costs generates an increase in the number of firms, a decrease in the markup, and an increase in the capital stock. For instance, for $\alpha=0.35, r=0.02, \delta=0.06, b=10, \partial m / \partial \bar{c}$ is negative if the markup $\mu$ is lower than $157 \%$. Thus, a reduction in entry costs leads to an increase in the number of firms and a lower mark up. ${ }^{11}$

Let's now consider the steady state effect of a change in the adjustment cost parameter, allowing for a change in the equilibrium number of firms that may occur as a result of variations in $b$. In the long-run with $m$ variable, the total effect is $d k / d b=(\partial k / \partial b)+(\partial k / \partial m)(\partial m / \partial b)$. As shown above, deregulation captured by a decrease in $b$ has a positive effect on the capital stock, for a given $m$, since $\partial k / \partial b<0$. Also, $(\partial k / \partial m)>0$. However, it is not possible to sign $\partial m / \partial b$, and, hence, the total effect, without additional assumptions. Again, some algebra leads us to conclude that, under a Cobb-Douglas technology, the condition in (11) guarantees that $d k / d b<0$. Hence, also in this case, a regulatory reform that decreases the cost for the firm to adjust their capacity leads to a higher level of the capital stock in the long-run.

The general conclusion that can be derived from the models we have analyzed so far is that deregulation of product markets has a positive effect on capital accumulation if it generates a reduction in the markup of prices over marginal costs (for instance through a reduction in entry barriers) or if it lowers costs of adjusting the capital stock.

\subsection{Two additional channels}

Regulation can affect investment through two additional channels. The first channel is operative when regulation imposes a ceiling on the rate of return on capital invested in some sectors. If the constraint binds, the choice of factor proportion may be altered in favor of more capital intensive techniques and the amount of capital used increases relative to the one chosen in the absence of constraints. This is the well know argument due originally to Averch and Johnson (1962) and refined, subsequently, by other authors. ${ }^{12}$ The basic idea is that by investing in additional capital, firms increase the base to which the (constrained) rate of return is applied, resulting in a greater total remuneration for capital. The consequence is that re-

\footnotetext{
${ }^{11}$ If the production function is $F\left(K_{i}, L_{i}\right)-\Phi$, in order to allow for increasing returns, the term $-\frac{\Phi m}{\bar{L}}$ should be included on the lhs of (10) making more likely that a decrease in entry costs increases $\mathrm{m}$. The sufficient condition in (11) remains unchanged.

${ }^{12}$ See also Takayama (1969) and Baumol and Klevorick (1970). The relevance of the AverchJohnson model has been debated empirically, typically in the power generating sector, with mixed results. See, for instance, Petersen (1975) and Boyes (1976).
} 
duction in the rate of return on capital below the profit maximizing level (resulting from the imposition of a binding ceiling) leads to an increase in the capital stock. The lower the allowed rate of return is, the greater is the capital stock employed by the firm. ${ }^{13}$ Removing the binding constraint would, instead, reduce the desired capital stock and therefore investment.

The second argument has to do with the presence of public or semi-public enterprises, which in many countries accounted for a large fraction of production in some sectors such as utilities and transport, and also in the manufacturing sector. Product market regulatory reforms that have taken place in the last decades have often been accompanied by privatization. The disappearing or reduced importance of a dominant publicly owned player, facing a soft budget constraint, is one of the reasons why deregulation has lead to a decrease in entry barriers for new privately owned firms. The model with entry costs we have analyzed above captures therefore the shrinking role of public enterprises if we think of $\bar{c} K_{i}$ as a shadow cost.

However, public enterprises may have been heavy investors because of a political mandate imposed on them or because of their managers's incentives. Managers of public enterprises often behave as empire builders, because their reward in terms of monetary compensation, power, and perks may be related to the size of the organization. It is also unlikely that capital markets can effectively restrict this type of behavior. Alternatively, their objective may be to maximize political support, and this may lead to set prices below the profit maximizing level (Peltzman (1971)). Thus, one may have overexpansion and over-investment in public enterprises, so that with privatization total investment might fall. In order to disentangle the multifaceted effects of privatization one would need a break down of data on an internationally comparable basis of investment by sectors and by type of firm: private, private with public participation, public, etc. Unfortunately, these data are not available. Therefore, if total investment increases after a policy change that implies both privatization and a lowering of entry barriers, it may mean that the increase of private investment more than compensate the possible fall of investment in privatized enterprises.

\subsection{Summing up}

The effect of "deregulation" on investment is in theory at least ambiguous. Reforms which imply reduction in entry barriers or in the markup tend to lead to an increase

\footnotetext{
${ }^{13}$ One can obtain similar predictions if the regulatory authority sets directly the (relative) prices firms can charge and mandates that firms satisfy all demand at those prices. If prices are set below the (monopoly) maximizing prices output demanded would rise relative to the unconstrained case. As a result the demand of both capital and labor would be higher, for given factor prices.
} 
in investment. Aspects of deregulation that remove binding constraints on rates of return or imply privatization of public or semi-public enterprises may determine a reduction of investment. In the end, the answer has to be found empirically. The previous discussion will guide us in what aspects of deregulation should have which effect on investment.

\section{The Data}

For our empirical assessment of the effects of product market regulation we use time varying measures of regulation for several non manufacturing industries in OECD countries, for which investment, capital and value added data are also available. In the two next subsections we describe in detail the construction of the main variables used in estimation.

\subsection{The Industry-Level Regulation Data}

In order to capture the intensity of regulation, we use data collected and described by Nicoletti et al. (2000), who extended the cross-sectional data contained in the OECD International Regulation Database. These data are used to construct time-series indicators of overall regulation, barriers to entry and public ownership from 1975 to 1996 in 21 OECD countries (Australia, Austria, Belgium, Canada, Switzerland, Germany, Denmark, Spain, Finland, France, UK, Greece, Ireland, Italy, Japan, the Netherlands, Norway, Portugal, Sweden, US, New Zealand) for seven non-manufacturing industries: electricity and gas supply (generation, transmission, distribution), road freight, air passenger transport, rail transport, post (basic letter, basic parcel and express mail) and telecommunications (fixed and mobile). The regulatory indicators measure on a scale from 0 to 6 (from least to most restrictive) restrictions on competition and private governance.

The summary index of regulation includes information on entry barriers, public ownership, the market share of new entrants (in the telephone, gas and railroad sectors), and price controls (in the road freight industry). Entry barriers cover legal limitations on the number of companies in potentially-competitive markets and rules on vertical integration of network industries. The barriers to entry indicator takes a value of 0 when entry is free (i.e.: a situation with three or more competitors and with complete ownership separation of natural monopoly and competitive segments of the industry) and a value of 6 when entry is severely restricted (i.e.: situations with legal monopoly and full vertical integration in network industries or restrictive licensing in other industries). Intermediate values represent partial liberalization of entry (e.g. legal duopoly, mere accounting separation of natural 
monopoly and competitive segments). Public ownership measures the share of equity owned by central or municipal governments in firms of a given sector. The two polar cases are no public ownership ( 0 value of the indicator) and full public ownership (a value of 6 for the indicator). Whenever data are available (i.e. mainly for network industries), intermediate values of the public ownership indicator are calculated as an increasing function of the actual share of equity held by the government in the dominant firm. In some cases (e.g. the energy industries), a simple three-pronged scale is used pointing to full or majority control by the government (a value of 6), mixed public/private ownership (a value of 3), marginal public share or full private ownership (a value of 0 ). ${ }^{14}$

The construction of the indicators involved the following steps. First, separate indicators for barriers to entry, public ownership, market share of new entrants, and price controls were created at the finest available level of industry disaggregation (e.g. production, transmission and distribution of electricity and gas; mobile and fixed telephony; letter, parcel and express mail). Second, these indicators were aggregated at the industry level taking simple averages or revenue-weighted averages (when aggregating horizontal segments of industries, such as mobile and fixed telephony). Third, the index of overall regulation is obtained by averaging in each of the seven industries the indicators of barriers to entry, public ownership, market share of new entrants, and price controls. Finally, we used simple averaging of the indices to reach the level of industry aggregation for which investment and value added data are available. More specifically, we have aggregated the regulation indices for the seven sectors in the three broader sectors: utilities (electricity and gas), communication (telecommunications and post), and transportation (airlines, road freight and railways).

In our regressions we use four different indicators of regulation: $R E G O L$, the overall indicator including all the regulation dimensions; $R E G N O$, which includes all dimensions except public ownership; $B E V I$, which summarizes barriers to entry (comprising legal restrictions and vertical integration), and $R E G P O$, which includes only public ownership information. The reason for isolating the effect of public ownership is that, in principle, public ownership per se does not imply rules and restrictions that private investors have to follow. However, it is likely to influence the shadow cost of entry for private firms. Moreover, as discussed above, investment choices of public enterprises may differ from those of private firms. The market share of new entrants will not be used individually as an explanatory variable. It is certainly useful to measure the effectiveness of entry liberalization in promoting competition, but, as an outcome variable, it is also the component most affected by potential endogeneity problems. Finally, we do

\footnotetext{
${ }^{14}$ Public ownership is irrelevant in the road freight industry of OECD countries.
} 
not use the indicator of price controls by itself because data on price controls are available only for the road freight industry.

Figure 1 plots the level of regulation, as measured by the summary indicator $R E G O L$, in 1975 and in 1998 on the horizontal and vertical axis respectively. Countries-sectors differ both in terms of the level of regulation and in terms of changes in the regulatory environment. All the observations are below the 45 degree line indicating a general trend toward liberalization and privatization. Interestingly, no country except the US had low regulation at the beginning of the sample in the three broad industry aggregates. The US was the least regulated economy at the beginning of the sample, was still so in 1998, and implemented strong deregulation policies over the period. For example, the index measuring the level of regulation in the US in the transport sector is equal to 4.25 in 1975 and to 0.75 in 1998 , a decrease of about $82 \%$. Deregulation has also been particularly strong in the UK and New Zealand, which were highly regulated at the beginning of the sample, while they rank among the most "market-oriented" economies in 1998. For example, regulation decreased by $86 \%$ from 5.5 to 0.75 in the transport sector in New Zealand and by $78 \%$ (from 5.63 to 1.25 ) and 69\% (from 5.08 to 1.58 ) in the utilities and communications sectors in the UK. On the contrary, countries like Italy, France, Greece were among the most regulated economies in 1975 and were still so in 1998.

The timing of regulatory reforms also differs across countries. Figures 2 and 3 plot the average across all seven non-manufacturing industries of the index $B E V I$ and $R E G P O$ for the following representative countries: US, UK, New Zealand, Germany, France, Spain and Italy. While the first three countries reduced entry barriers starting from the late seventies/early eighties, in Italy and Spain the process did not begin till the nineties, and in France and Germany the changes that occurred during the eighties were minor. The index measuring the extent of public ownership points to a generalized trend towards privatization. Once again, the process has been rather timid in Italy and France and much more decisive in New Zealand and UK. Note that the US is the only country that does not show a tendency to reduce public enterprises. However, the US had the smallest beginning of period level of public ownership, much below the level of continental Europe.

\subsection{The Other Data}

Data on investment, capital stock, and value added at the country-sector-year level come from the OECD STAN database for Industrial Analysis, based on the International Standard Industrial Classification of all Economic Activities, Revision 3 (ISIC Rev. 3). This database covers both services and manufacturing sectors for the following OECD countries: Austria, Belgium, Canada, Germany, Denmark, 
Spain, Finland, France, UK, Italy, Japan, Netherlands, Sweden, and USA, starting from 1970. The non-manufacturing sectors most widely covered by the STAN database are: $(i)$ electricity, gas and water, (ii) communications and posts, (iii) transport and storage, and (iv) transport, storage and communications, for countries in which no separate data for communications and transport is available. From now on, we will name the sectors defined in (i), (ii), (iii), and (iv) utilities, $U$, communications, $C$, transport, $T$, and transport and communications, $T C$, respectively. We use the data at the most disaggregated level (sectors $U, C, T$ ) whenever they are available and data for sectors $U$ and $T C$ otherwise.

Our first panel ( $P$ anel $A$ ) includes sectors $U, C, T$ for Canada, Germany, Denmark, Finland, France, and UK, and sectors $U$ and $T C$ for Belgium and Italy. This panel still includes only eight OECD countries. In order to use more information on regulatory reforms in OECD countries we also construct a second panel (Panel $B)$, extending our basic panel with data from the OECD's International Sectorial Database (ISDB). Panel $B$ includes sectors $U, C, T$ for Belgium Canada, Germany, Denmark, Finland, France, UK, Italy, Sweden, sectors $U$ and $T C$ for Australia, and the US, and sector $U$ for Japan.

We merge the data contained in Panel $A$ and Panel $B$ with the database containing the regulation indices $R E G O L, R E G N O, B E V I$, and $R E G P O$. As mentioned above, because data on investment, capital, and value added are not available for each single industry for which regulation indices exist, we mapped the industry-level regulatory indicators into the four non-manufacturing aggregates covered by our STAN-ISDB industrial statistics database. In the empirical analysis, we analyze the effect of regulation on investment using both Panel $A$ and Panel $B$ and we show that our results are robust to the sample choice. Investment in utilities, transport and communication sectors is about $18 \%$ of business investment in OECD countries, approximately the same share as the one of investment in the manufacturing sector. Hence, our analysis on the effect of deregulation on investment is not limited to a trivial component of business sector investment in OECD countries.

Figure 4 plots the average of investment as a share of the capital stock in the utility, communications, and transport sectors in the US and UK (selected as the early and more decisive deregulators) and in the three largest continental European countries, Italy, France and Germany, (selected as late and timid deregulators). The pattern of the investment rate in one group of countries is the opposite of the other: while in US and UK investment as a share of the capital stock increased from $3.7 \%$ in 1975 to $8.15 \%$ in 1998 , in the large continental European countries the investment rate decreased by 5 percentage points from $9.4 \%$ to $4.4 \%$. As shown in figures 1-3, US and UK strongly liberalized product markets starting in the late seventies/early eighties, while deregulation reforms were almost absent in Italy, 
France and Germany till the nineties.

\section{Investment and Regulation: Econometric Results}

We now turn to the econometric evidence on the effect of regulation. We first discuss the results in the context of a simple dynamic panel model of investment and regulation, controlling for common or sector specific year effects. We show that proxies for regulation, in particular those that capture barriers to entry, have a significant negative effect on investment. We then present evidence that our conclusions are robust to various extensions and sensitivity checks.

\subsection{Basic Specification}

We base our investigation on estimation of various versions of an unrestricted dynamic model of investment of the form:

$(I / K)_{i j t}=\sum_{s=1}^{2} \alpha_{s}(I / K)_{i j t-s}+\sum_{s=0}^{2} \beta_{\eta} R E G_{i j t-s}+\gamma_{i}+\delta_{j}+\zeta_{t}+\left(\right.$ or $\left.\zeta_{j t}\right)+\varepsilon_{i j t}$

where $t$ represents years, $i$ denotes countries and $j$ sectors. $R E G$ is one of our four indices of regulation described above ( $R E G O L, R E G N O, B E V I$, and $R E G P O)$. The remaining terms capture country fixed effects, sector fixed effect, and common (or sector specific) year dummies. We estimate (12) by OLS. ${ }^{15}$

In Table 1 we present the results obtained with common year dummies. For compactness, we report the sum of the coefficients of the regulation variable (Sum) and a test for its equality to zero, which is the most relevant test to assess the longrun effect of regulation on investment. ${ }^{16}$ The value of the long-run multiplier is also shown in the table. We also report a test on the hypothesis that the coefficients

\footnotetext{
${ }^{15}$ OLS estimation with country and sector fixed effects yields consistent estimates since we have a panel with large $\mathrm{T}$.

${ }^{16}$ If we take the simple models of the previous section literally, regulation should not have a longrun effect on the investment rate, as the latter equals simply the depreciation rate in the steady state. However, even simple changes would invalidate this result. For instance, if adjustment costs are specified as in Uzawa (1969), so that gross investment turns into capital at a decreasing rate, changes in the adjustment cost parameter associated with deregulation will affect the steady state value of the investment rate (we have not used this model in the theoretical section because it is more complicated). More fundamentally, it is possible to envision endogenous growth models in which regulation may affect the steady state growth rate of the capital stock, and, hence, the investment rate. For this reason, in our econometric work, we let the data decide whether or not there is a long-run effect of regulation on the investment rate.
} 
of the index of regulation are jointly zero. Model 1 is the most general model, containing the contemporaneous, once lagged, and twice lagged value of the regulation variable. Model 2 restricts the coefficient on the contemporaneous value of the regulation index to be equal to zero, while Model 3 is the most restricted model as it only includes the once lagged value of the regulation indicator. For Model 2 the test on the joint equality to zero of the coefficients can be interpreted as a test of Granger causality (from regulation to investment). We present these three models to be sure that results are not sensitive to the number of lags of the regulatory index included in the regression. In particular, the specifications that do not include the contemporaneous value of the regulatory indicator (Model 2 and Model 3) are less open to criticisms about the endogeneity of the regulatory index itself.

Table 1 shows a significant negative effect of regulation on investment: the sum of the coefficients for summary measures of regulation (REGOL and $R E G N O$ ) is almost always significant at the $1 \%$ level across models and samples. The negative effect is due in particular to entry liberalization measures. In fact, while Sum for the barrier to entry variable $(B E V I)$ is always significant at the $1 \%, S u m$ for the measure of public ownership (REGPO) is never significant at the $5 \%$ level. The test of joint significance of the coefficients presents a similar picture, with marginal significance levels between $1 \%$ and $5 \%$ for $R E G O L$ and $R E G N O$ and equal to $1 \%$ in most cases for $B E V I$. Again, the coefficients for $R E G P O$ are never jointly different from zero at conventional levels. These results are robust to the exclusion of one country at the time.

In order to have an idea of the size of the effect of changes in regulation on investment, consider an exogenous unit decrease in $R E G O L$, for Panel A, Model 2. The investment rate increases by 1.1 percentage points in the long-run. Since the investment rate is approximately equal to $6 \%$ on average, this would imply an increase to $7.1 \%$. Note that if $R E G O L$ decreases from its third quartile value (5.7) to its first quartile value (3.4), this change generates an increase in the investment rate of approximately 2.5 percentage points, which is quite large. The same experiment for $B E V I$ leads to a total increase of 2.4 percentage points ( $B E V I$ changes from 6 to 3.6 going from the third to the first quartile). Consider also that the sectors in our panels are highly capital intensive: the capital to gross output ratio equals approximately 4.2 and the capital to value added ratio equals 6.5. As a result, the increase of investment as a percentage of gross output or value added is much larger. The figures for Panel B are somewhat smaller, but still sizeable: the total increase in the investment rate, following a change in $R E G O L$ from the third to the first quartile, would now be 1.8 percentage points in the long-run. The same experiment for $B E V I$ leads to an increase of 1.7 percentage points in the investment rate.

Another way of gathering a sense of the magnitude of the changes is to make 
some experiments with actual values of the indices in different time periods in one country or across countries. Consider, for example, the regulatory reforms implemented in the UK in the transport and communications sector. In the period 1975-1983, the overall index of regulation was constant and equal to 3.75 and the average value of the investment rate was 4.96 per cent. Starting from 1984, the index $R E G O L$ shows a trend toward deregulation and reaches a value of 0.78 in the period 1994-1998. Our model predicts an increase in the investment rate in the long-run of 3.27 percentage points (from $4.96 \%$ to $8.23 \%$ ) using the coefficients of Model 2 Panel A. The actual increase was 3.03 percentage points (from $4.96 \%$ to 7.99\%).

Lets' now compare average values of the regulation indicator $R E G O L$ across countries. For instance, in the period 1994-1998, the average value of $R E G O L$ in the transport and communication sectors is 0.80 in US, 3.42 in Germany and in France, and 4.57 in Italy. The investment rate is $8.97 \%$ in US, $5.6 \%$ in Germany, $5.9 \%$ in France, and $6.8 \%$ in Italy. One can compute that if Germany and France regulation changes from 3.42 - their own value - to the US one equal to 0.80, Model 2 Panel A predicts an increase in the investment rate by 2.62 percentage points in the long-run, from Germany's average value of 5.6\% to $8.22 \%$ and from France's average value of $5.9 \%$ to $8.52 \%$, much closer to the US average level of $8.97 \%$. Finally, suppose that regulation in Italy changes from 4.57 - its own value - to the US one equal to 0.8 , the model predicts an increase in the investment rate by 4.15 percentage points, from 6.8 per cent to 10.9 per cent.

In Table 2, which mimics Table 1, we report the results obtained when we include sector-specific year effects. This set of results is very important because technological advances, that are likely to have a sector specific component, were occurring at the same time of regulatory reform. Table 2 shows that, even after controlling for sector-specific year dummies, the test on Sum still suggests a significant negative effect of $R E G O L$ and $B E V I$ in both Panel A and Panel B, even though the results of the test of joint significance of the coefficients are weaker. However, the value of the long-run coefficients are very similar to those obtained in Table 1. The results on the negative effects of $R E G N O$ are now somewhat weaker, while the ones on the lack of significance of the share of public ownership are confirmed. These results are consistent with our theoretical discussion, where we have shown that a reduction in barriers to entry is likely to have a positive effect on investment because it leads to a reduction of the markup and, possibly, of the cost associated with capital expansion. However, when it comes to privatization it is more difficult to predict the direction of its effect on investment. 


\subsection{Total Investment, Private Investment and Investment by Public Enterprises}

We have shown that deregulation increases total investment, which includes both private investment and investment by public or semi public enterprises. Ideally we would like to separate the two, but data limitations do not allow us to do so. Data for selected countries (and periods) show that investment of public enterprises has decreased, especially in Europe, probably as a result of tighter budget constraints faced by public enterprises and of the process of privatization. ${ }^{17}$ As we discussed earlier, political mandates imposed on public enterprises and/or their own internal logic may lead to overinvestment. However, privatization may also generate more profit opportunities for private firms. As a result, if deregulation of product market and privatization of public enterprises are positively correlated and if the first (second) effect dominates one may underestimates (overestimates) the impact of deregulation on private investment. The correlation between our index of public ownership (REGPO) and the index of all other aspects of the regulatory environment excluding public ownership $(R E G N O)$ is indeed around 0.6. In order to control for changes in investment of public enterprises and to assess the direction of the bias (if any), we have estimated regressions in Table 1 including both $R E G P O$ and $B E V I$ or REGPO and REGNO on the rhs of equation (12). Sum for $R E G P O$ is never significant at the $5 \%$ level and the coefficients of $R E G P O$ are not jointly different from zero at conventional levels. Moreover, the significance and size of the effect of $B E V I$ and $R E G N O$ on investment is unchanged, suggesting the absence of any sizable bias. For instance, for Panel A, Model 2, Sum for the barrier to entry variable $(B E V I)$ is equal to -0.0015 and significant at the $1 \%$, and an exogenous unit decrease in $B E V I$ leads to an increase of the investment rate of 0.95 percentage points in the long-run. For the same model in Table 1, column 3, the sum of the coefficients for $B E V I$ is -0.0016 and the long-run effect of a unit decrease in $B E V I$ on the investment rate is 1 percentage point.

\subsection{Controlling for Country Specific Shocks and Sectorial Output}

Next we control for country specific shocks. We summarize here the main conclusions. Detailed results are available upon request. More specifically, we have first added to the specifications of Table 1 the cyclically-adjusted value of the ratios between government expenditure and tax revenue to GDP. Alesina et al. (2002)

\footnotetext{
${ }^{17}$ For instance in the period 1982-1998 non-agricultaral business investment of public enterprises went down from about 30 per cent of total non-agricultural business investment to about 10 per cent in Italy and Portugal and from about 16 per cent to 12 per cent in Germany and Belgium (see CEEP, various years). See also Bertero and Rondi (2002) for evidence that tighter budget constraints has led to a decrease in investment by public enterprises in Italy.
} 
show that public spending, and to a lesser extent taxation, exert a negative effect on aggregate investment in the context of a $Q$ model. Our basic results are virtually unchanged with the inclusion of these variables. As an aside, note that public spending and taxation have a negative, but not significant effect on the sectorial investment rates. These results are at least weakly consistent with those of Alesina et al. (2002).

Second, we have included the GDP-to-capital ratio of the business sector and the real ex-post interest rate (defined as the nominal long interest rate at time $t$ minus the inflation rate between $t+1$ and $t$ ) and results are virtually unchanged. Finally, we checked whether results are robust when we control for liberalization in the labor market. We measure regulation in the labor market using OECD data on employment protection, replacement rate, bargaining coordination, bargaining centralization, degree of corporativism and union density. We enter each variable, lagged once and twice, one at a time. Once again, our conclusions on the long-run effect of regulation on investment are unaffected. Note also that the labor market indicators do not have a statistically significant long-run effect on the sectorial investment rates. In fact, the sum of the coefficients on the first and second lag of the labor market indicators is not significant except when we use data on the degree of corporativism. In this case, the estimates suggest that an increase in corporativism reduces investment. ${ }^{18}$

Our next experiment consists of adding the value added-to-capital ratio, lagged once and twice, as additional regressors to Model 2 of Table 1. Results for Panel $\mathrm{B}$ are in Table $3 .{ }^{19}$ This specification can be rationalized as the linear approximation of a model with quadratic adjustment costs and a Cobb-Douglas production function. ${ }^{20}$ The sum of the coefficients on the value added to capital terms (Sum2)

\footnotetext{
${ }^{18}$ The correlation between our summary measure of regulation $R E G O L$ and the union density and the replacement rate variables is equal 0.18 ; the correlation between $R E G O L$ and the employment protection index is 0.68 , while the correlation between $R E G O L$ and the remaining indices measuring regulation in labor markets is around 0.4.

${ }^{19}$ For brevity sake, here and in the following tables, we present only the results for Model 2 estimated for Panel B. Results are similar for Model 1 and 3 and for Panel A.

${ }^{20}$ At each point in time the marginal revenue product of capital equals $(\alpha /(1+\mu))(Y / K)$, where $\alpha$ is the elasticity of output with respect to capital, $\mu$ as usual is the markup, and $Y$ denotes value added. Investment will be an increasing function of the present discounted value of the marginal revenue product of capital (with coefficient $1 / b$, assumed constant for simplicity). Take a linear approximation of the shadow value of capital around the sample average values of $\mu$ and $Y / K$. Assume then that the markup is a linear function of regulation and that forecasts for regulation and $Y / K$ are based on a simple bivariate $\mathrm{AR}(2)$ system. This would lead to a model of investment that includes two lagged values of the proxy for regulation and $Y / K$. Note also that at each point in time deregulation increases marginal revenue because it leads to a decrease in the markup. At the same time, this model would suggest that increased capital intensity is associated with a decrease in $Y / K$. Our theoretical analysis suggests that the first effect should dominate since the investment rate
} 
are significant and so are the sum of the coefficients for the regulatory indices REGOL, REGNO, and BEVI (Sum 1). The size of the effect of deregulation on investment changes only marginally. Hence, our results are robust when we control for the effect of changes in output on investment.

If we want to calculate the overall impact of regulation, it is also necessary to know the effect of regulation on the value added-to-capital ratio. In Table 4 we present the results obtained when regressing $Y / K$ on two lagged value of itself and two lagged values of the regulation indices. Interestingly, while one can reject the joint equality to zero of the regulation coefficients, their sum is basically zero and insignificant. This means that the long-run coefficient of regulation in the investment equation adequately captures its effect.

\subsection{Heterogeneity in Short-Run Response}

So far we have assumed that the response to regulation is the same across sectors and countries. We now allow for heterogeneity in short-run responses, while maintaining the assumption of an identical long-run effect. We begin by reparametrizing Model 2 as follows:

$$
\begin{aligned}
\Delta(I / K)_{i j t}= & \vartheta_{1} \Delta(I / K)_{i j t-1}+\lambda_{1} \Delta R E G_{i j t-1}+\vartheta_{2}(I / K)_{i j t-2}+ \\
& +\lambda_{2} R E G_{i j t-2}+\gamma_{i}+\delta_{j}+\zeta_{t}+\varepsilon_{i j t}
\end{aligned}
$$

where $\vartheta_{1}=\left(\alpha_{1}-1\right), \lambda_{1}=\beta_{1}, \vartheta_{2}=\left(\alpha_{1}+\alpha_{2}-1\right), \lambda_{2}=\left(\beta_{1}+\beta_{2}\right)$, and $\alpha_{1}, \alpha_{2}, \beta_{1}$, and $\beta_{2}$ are the coefficients in equation (12). In equation (13), the long-run effect of regulation is captured by $\lambda_{2} / \vartheta_{2}$, while the short-run response depends upon $\lambda_{1}$ and $\vartheta_{1}$. We let the coefficients $\lambda_{1}$ and $\vartheta_{1}$ differ across countries or across sectors. We find that regulation does not have a statistical significant effect on investment in the short-run, in the sense that $\lambda_{1}$ is not statistically significant. The only exception occurs in the specification in which $\lambda_{1}$ differs across sectors and regulation is measured by $R E G O L$ or $R E G N O$. In this case, for the communications sector, a one unit decrease in $R E G O L$ or $R E G N O$ leads to an increase in investment as a share of the capital stock of 0.6 and 0.37 percentage points, respectively, after one year. ${ }^{21}$ Second, results on the long-run effect of regulatory reforms on investment in Table 1 are virtually unchanged when allowing the short-run coefficients to differ across countries (see Table 5, Part I) or across sectors (see Table 5, Part II). In fact, $R E G O L, R E G N O$, and $B E V I$ have a negative and statistically significant effect (at the $5 \%$ level or better) on investment and the size of the coefficients is very close to the one in Table 1. REGPO, instead, is significant at the $10 \%$ level

increases following a deregulation that generates a decrease in the markup.

${ }^{21}$ Results are not shown and are available upon request. 
only when the coefficients $\vartheta_{1}$ and $\lambda_{1}$ vary across sectors, but not when they vary across countries.

\subsection{Non-linear Effects of Regulatory Reforms}

We now investigate whether there is evidence of a non linear response of investment to regulatory changes. To start with, we check whether the long-run effect of regulation on investment depends on the level of regulation itself. In particular, we add to Model 2, reparametrized as in equation (13), the square of the variable $R E G_{i j t-2}$. Results are reported in Table 6, Part I. For the summary measures of regulation, $R E G O L$ and $R E G N O$, and for $B E V I$, the coefficients on the linear term $R E G_{i j t-2}$ remains negative and significant, while the coefficient on the square term is positive and significant at the $10 \%$ level for $R E G O L$ and $R E G N O$, and at the $5 \%$ level for $B E V I$. This implies that regulation has a negative effect on investment but the magnitude of the effect decreases as the index of regulation increases. Consider, for example, $B E V I$. The effect of regulation is zero when $B E V I$ equals 5.68. The effect of regulation on investment is negative for $B E V I<5.68$ and it is positive if $B E V I>5.68$. Considering that the maximum value of $B E V I$ is 6 , this result shows that basically regulation has a negative effect on investment almost for every value of the index and then it flattens out.

Another interesting experiment is to see whether the long-run effect of regulation on investment also depends on the magnitude of the change occurred in regulation between 1975 and 1998 . We interact the variable $R E G_{i j t-2}$ in equation (13) with two dummy variables, LARGE and SMALL. LARGE (SMALL) is equal to one if the change in the regulation index between 1975 and 1998 is bigger (smaller) than the median change in the sample and zero otherwise. Results are reported in Table 6, Part II. We find that regulation has a significant negative effect on investment both when its change is "large" and when it is "small" if we measure regulation with the overall indices $R E G O L$ and $R E G N O$. The effect tends to be greater for large changes. Instead, the coefficient of $B E V I$ is statistically significant at the $5 \%$ level only when interacted with the dummy variable $L A R G E$. It is significant at the $10 \%$ when interacted with $S M A L L$. Moreover, the coefficient is greater in the former case (-0.0011 versus -0.0007), implying a long-run effect on investment of a one unit decrease in $B E V I$ of 0.6 percentage points. The long-run increase in investment is 0.4 percentage points when the overall decrease in regulation is small. However, a test on the equality of the coefficients can only be rejected at the $7 \%$ level. Note also that a decrease in public ownership has a negative and significant effect at the $10 \%$ level only when governments implemented large scale privatization programs. Otherwise the effect is insignificant.

Finally, in Table 6 Part III, we investigate whether the timing of regulatory 
reforms matters. More specifically, we check whether deregulation of product markets positively affects investment both in countries that have undertaken reforms early on in the sample and in the "late deregulators" countries. We define two dummy variables, $L A T E$ and $E A R L Y$. LATE (EARLY) is equal to one in countries-sectors where we do not observe (do observe) any decrease in regulation before 1990 and zero otherwise. As before, we interact the variable $R E G_{i j t-2}$ in equation (13) with the two dummy variables. We find that deregulation has a negative and statistically significant effect only when interacted with the dummy $E A R L Y$. In countries-sectors that begin deregulating product markets in the 1990 's, a one unit decrease in regulation has no impact on investment. Moreover, the coefficient of the dummy variable $L A T E$ is negative and statistically significant in all specifications except when we use the index $R E G P O$.

Note that one may fail to find a statistical significant effect on investment in "late deregulators" simply because there is not enough variations in the regulation data. However, it is also the case that countries that were opened up to competition earlier in the sample are those that deregulated more deeply. Finally, our conclusions on the lack of short-run effects still hold and we do not find any consistent and robust evidence on short-run effects even when we allow for a non-linear response of investment to regulation in the short-run.

\section{Conclusions}

Tight regulation of the product markets has had a large negative effect on investment. The data for sectors that have experienced significant changes in the regulatory environment suggest that deregulation leads to greater investment in the long-run. The component of reforms that plays the most important role is entry liberalization, while industry-level measures of privatization do not seem to affect investment significantly. This is consistent with what one would expect a priori. A reduction in entry barriers leads to a reduction of the markup and, hence of the penalty of expanding production, in terms of lost monopoly profits. This leads to greater investment. However, when it comes to public ownership, there are contrasting forces at work. While a reduction in public ownership can be seen as a reduction in the shadow cost of entry, agency problems affecting the behavior of public managers may lead to over-accumulation of capital. These results are robust to several sensitivity checks and extensions. Interestingly, we also find that the marginal effect of deregulation depends on how deep the change is: more decisive regulatory reforms have a greater marginal impact. Moreover, the marginal effect is greater when one starts from lower levels of regulation. The implication of our analysis is clear: regulatory reforms that substantially lower entry barriers 
spur investment. 


\section{References}

[1] Abel A.B. and Blanchard O.J, (1983), "An Intertemporal Model of Saving and Investment", Econometrica, vol. 51, issue 3, pp. 675-692.

[2] Alesina A., S. Ardagna, R. Perotti, and F. Schiantarelli, (2002), "Fiscal Policy, Profits, and Investment", American Economic Review, vol. 92, no. 3, June 2002, pp. 571-589.

[3] Averech H. and L. L. Johnson, (1962), "Behavior of the Firm Under Regulatory Constraint", American Economic Review, vol 52 December, pp. 10531069.

[4] Bassanini A. and Ernst, (2002), "Labor Market Institutions, Product Market Regulations and Innovation: Cross Country Evidence", OECD Economics Department Working Papers, No. 316.

[5] Baumol W. J. and A. K. Klevorick, (1970), "Input Choices and Rate of Return Regulation, an Overview of the Discussion", The Bell Journal of Economics, pp. 162-19.

[6] Bertero E. and L. Rondi, (2002), "Does a Switch of Budget Regimes Affect Investment and Managerial Discretion of State-Owned Enterprises? Evidence from Italian Firms", Journal of Comparative Economics, vol. 30, n. 4, pp. 836-863.

[7] Blanchard O.J., and F. Giavazzi, (2001), "Macroeconomic Effects of Regulation and Deregulation in Goods and Labor Markets", NBER working papers, No. 8120 .

[8] Blanchard, O.J.. and R. Perotti, (2002), "An Empirical Investigation of the Dynamic Effects of Changes in Government Spending and Revenues on Output", Quarterly Journal of Economics, November, pp. 1329-1368.

[9] Blanchard O.J., and J. Wolfers, (2000), "The Role of Shocks and Institutions in the Rise of European Unemployment: The Aggregate Evidence", Economic Journal, vol. 110, no. 462.

[10] Boyes W. J., (1976), “An Empirical Examination of the Averech-Johnson Effect", Economic Enquiry.

[11] CEEPP (Center Europeen des Enterprises a Partecipation Publique), Annales, various issues, Bruxells. 
[12] Djankov S., R. La Porta, F. Lopez-De-Silanes, and A. Shleifer, (2002), "The Regulation of Entry”, Quarterly Journal of Economics, February, pp. 1-37.

[13] Joskow P. L., and N. L. Rose, (1989), “The Effects of Economic Regulation”, in Handbook of Industrial Organization, vol. II, edited by R. Schmalensee and R.D. Willig, Elsevier Science Publishers B. V.

[14] Nickell S., (1996), "Competition and Corporate Performance", Journal of Political Economy, vol. 104, pp. 724-746.

[15] Nicoletti, G., R.C.G. Haffner, S. Nickell, S. Scarpetta and G. Zoega (2001a), "European Integration, Liberalization, and Labor Market Performance", in Bertola G., T. Boeri and G. Nicoletti (eds.) Welfare and Employment in United Europe, MIT Press, Cambridge, MA.

[16] Nicoletti G., A. Bassanini, E. Ernst, S. Jean, P. Santiago, and P. Swaim, (2001b), "Product and Labor Markets Interactions in OECD Countries", OECD Economics Department Working Papers, No. 312, OECD, Paris.

[17] Nicoletti G., and S. Scarpetta, (2002), "Regulation, Productivity, and Growth", forthcoming in Economic Policy.

[18] Nicoletti G. , S. Scarpetta, and O. Boylaud, (2000), "Summary Indicators of Product Market Regulation with an Extension to Employment Protection Legislation”, OECD Economics Department Working Papers, No. 226, OECD, Paris.

[19] Peltzman S, (1971), "Pricing in Public and Private Enterprises, Electric Utilities in the United States", Journal of Law and Economics, 14, April pp 109147.

[20] Petersen H. C., (1975), “An Empirical Test of Regulatory Effects”, Bell Journal of Economics, Spring.

[21] Rotemberg and Woodford, (1995), "Dynamic General Equilibrium Models with Imperfectly Competitive Product Markets" in Frontiers of Business Cycle Research, T.Cooley (ed).

[22] Spector D., (2002), "Competition and The Capital- Labor Conflict", CEPREMAP - CNRS Discussion Paper, No. 2002-07.

[23] Takayama A, (1969), "Behavior of the Firm Under Regulatory Constraint", American Economic Review, vol 59 June pp 255-260. 
[24] Uzawa H. (1969), "Time Preference and the Penrose. Effect in a Two-Class Model of Economic Growth", Journal of Political Economy, 77, pp. 628-652.

[25] Winston C., (1993), "Economic Deregulation: Days of Reckoning for Microeconomists", Journal of Economic Literature, September 1993, pp. 12631289. 


\begin{tabular}{|c|c|c|c|c|}
\hline & \multicolumn{4}{|c|}{ Panel A } \\
\hline & REGOL & REGNO & BEVI & REGPO \\
\hline Model 1 & & & & \\
\hline $\operatorname{Sum}=\beta_{0}+\beta_{1}+\beta_{2}$ & $-0.0018^{* *}$ & $-0.0014^{* *}$ & $-0.0015^{* *}$ & $-0.0007^{*}$ \\
\hline Pvalue test on $H_{0}:$ Sum $=0$ & 0.0044 & 0.015 & 0.0028 & 0.09 \\
\hline Long - run coefficient $=\left(\beta_{0}+\beta_{1}+\beta_{2}\right) /\left(1-\alpha_{1}-\alpha_{2}\right)$ & -0.0112 & -0.009 & -0.0097 & -0.005 \\
\hline Pvalue test on $H_{0}: \beta_{0}=\beta_{1}=\beta_{2}=0$ & 0.04 & 0.051 & 0.009 & 0.16 \\
\hline Nobs & 352 & 352 & 352 & 352 \\
\hline \multicolumn{5}{|l|}{ Model $2\left(\beta_{0}=0\right)$} \\
\hline Sum $=\beta_{1}+\beta_{2}$ & $-0.0017^{* *}$ & $-0.0014^{* *}$ & $-0.0016^{* *}$ & $-0.0007^{*}$ \\
\hline Pvalue test on $H_{0}:$ Sum $=0$ & 0.0042 & 0.011 & 0.0013 & 0.11 \\
\hline Long - run coefficient $=\left(\beta_{1}+\beta_{2}\right) /\left(1-\alpha_{1}-\alpha_{2}\right)$ & -0.011 & -0.0095 & -0.0102 & -0.0048 \\
\hline Pvalue test on $H_{0}: \beta_{1}=\beta_{2}=0$ & 0.016 & 0.022 & 0.004 & 0.10 \\
\hline Nobs & 352 & 352 & 352 & 352 \\
\hline \multicolumn{5}{|l|}{ Model $3\left(\beta_{0}=\beta_{2}=0\right)$} \\
\hline$\beta_{1}$ & $-0.0016^{* *}$ & $-0.0014^{* *}$ & $-0.0015^{* *}$ & -0.0005 \\
\hline Pvalue test on $H_{0}: \beta_{1}=0$ & 0.0056 & 0.0062 & 0.0009 & 0.244 \\
\hline Long - run coefficient $=\beta_{1} /\left(1-\alpha_{1}-\alpha_{2}\right)$ & -0.0113 & -0.010 & -0.011 & -0.004 \\
\hline \multirow[t]{3}{*}{ Nobs } & 362 & 362 & 362 & 362 \\
\hline & \multicolumn{4}{|c|}{ Panel B } \\
\hline & REGOL & REGNO & BEVI & REGPO \\
\hline Model 1 & & & & \\
\hline$S u m=\beta_{0}+\beta_{1}+\beta_{2}$ & $-0.0012 * *$ & $-0.001^{* *}$ & $-0.001^{* *}$ & $-0.0006^{*}$ \\
\hline Pvalue test on $H_{0}:$ Sum $=0$ & 0.005 & 0.016 & 0.008 & 0.076 \\
\hline Long - run coefficient $=\left(\beta_{0}+\beta_{1}+\beta_{2}\right) /\left(1-\alpha_{1}-\alpha_{2}\right)$ & -0.007 & -0.007 & -0.006 & -0.004 \\
\hline Pvalue test on $H_{0}: \beta_{0}=\beta_{1}=\beta_{2}=0$ & 0.028 & 0.03 & 0.009 & 0.24 \\
\hline Nobs & 578 & 578 & 578 & 578 \\
\hline \multicolumn{5}{|l|}{ Model $2\left(\beta_{0}=0\right)$} \\
\hline Sum $=\beta_{1}+\beta_{2}$ & $-0.0013^{* *}$ & $-0.001^{* *}$ & $-0.001^{* *}$ & $-0.0006^{*}$ \\
\hline Pvalue test on $H_{0}:$ Sum $=0$ & 0.003 & 0.008 & 0.003 & 0.07 \\
\hline Long - run coefficient $=\left(\beta_{1}+\beta_{2}\right) /\left(1-\alpha_{1}-\alpha_{2}\right)$ & -0.008 & -0.007 & -0.007 & -0.004 \\
\hline Pvalue test on $H_{0}: \beta_{1}=\beta_{2}=0$ & 0.013 & 0.02 & 0.011 & 0.12 \\
\hline Nobs & 578 & 578 & 578 & 578 \\
\hline \multicolumn{5}{|l|}{ Model $3\left(\beta_{0}=\beta_{2}=0\right)$} \\
\hline$\beta_{1}$ & $-0.0012^{* *}$ & $-0.001^{* *}$ & $-0.001^{* *}$ & -0.0005 \\
\hline Pvalue test on $H_{0}: \beta_{1}=0$ & 0.0044 & 0.007 & 0.003 & 0.11 \\
\hline Long - run coefficient $=\beta_{1} /\left(1-\alpha_{1}-\alpha_{2}\right)$ & -0.0075 & -0.007 & -0.006 & -0.003 \\
\hline Nobs & 600 & 600 & 600 & 600 \\
\hline
\end{tabular}

Notes: Dependent variable $(I / K)_{i j t}$ defined as investment divided by the capital stock of country $i$, sector $j$, year $t$.

Regulation indices used: REGOL, REGNO, BEVI, REGPO.

Country fixed effects, sector fixed effects, and common year dummies are included.

Model 1: $(I / K)_{i j t}=\sum_{s=1}^{2} \alpha_{s}(I / K)_{i j t-s}+\sum_{s=0}^{2} \beta_{s} R E G_{i j t-s}+\gamma_{i}+\delta_{j}+\zeta_{t}+\varepsilon_{i j t}$.

Model 2: $(I / K)_{i j t}=\sum_{s=1}^{2} \alpha_{s}(I / K)_{i j t-s}+\sum_{s=1}^{2} \beta_{s} R E G_{i j t-s}+\gamma_{i}+\delta_{j}+\zeta_{t}+\varepsilon_{i j t}$.

Model 3: $(I / K)_{i j t}=\sum_{s=1}^{2} \alpha_{s}(I / K)_{i j t-s}+\beta_{1} R E G_{i j t-1}+\gamma_{i}+\delta_{j}+\zeta_{t}+\varepsilon_{i j t}$.

$R E G$ stands for one of the following: REGOL, REGNO, BEVI, REGPO.

** Sum significant at the $5 \%$ level. * Sum significant at the $10 \%$ level. 


\begin{tabular}{|c|c|c|c|c|}
\hline & \multicolumn{4}{|c|}{ Panel A } \\
\hline & REGOL & REGNO & BEVI & REGPO \\
\hline \multicolumn{5}{|l|}{ Model 1} \\
\hline Sum $=\beta_{0}+\beta_{1}+\beta_{2}$ & $-0.0015^{* *}$ & $-0.001^{*}$ & $-0.0013^{* *}$ & $-0.0008^{*}$ \\
\hline Pvalue test on $H_{0}:$ Sum $=0$ & 0.026 & 0.10 & 0.02 & 0.07 \\
\hline Long - run coefficient $=\left(\beta_{0}+\beta_{1}+\beta_{2}\right) /\left(1-\alpha_{1}-\alpha_{2}\right)$ & -0.011 & -0.008 & -0.009 & -0.006 \\
\hline Pvalue test on $H_{0}: \beta_{0}=\beta_{1}=\beta_{2}=0$ & 0.17 & 0.35 & 0.06 & 0.13 \\
\hline Nobs & 352 & 352 & 352 & 352 \\
\hline \multicolumn{5}{|l|}{ Model $2\left(\beta_{0}=0\right)$} \\
\hline Sum $=\beta_{1}+\beta_{2}$ & $-0.0115^{* *}$ & $-0.0011^{*}$ & $-0.0014^{* *}$ & $-0.0007^{*}$ \\
\hline Pvalue test on $H_{0}:$ Sum $=0$ & 0.02 & 0.08 & 0.01 & 0.09 \\
\hline Long - run coefficient $=\left(\beta_{1}+\beta_{2}\right) /\left(1-\alpha_{1}-\alpha_{2}\right)$ & -0.011 & -0.009 & -0.010 & -0.006 \\
\hline Pvalue test on $H_{0}: \beta_{1}=\beta_{2}=0$ & 0.08 & 0.20 & 0.04 & 0.08 \\
\hline Nobs & 352 & 352 & 352 & 352 \\
\hline \multicolumn{5}{|l|}{ Model $3\left(\beta_{0}=\beta_{2}=0\right)$} \\
\hline$\beta_{1}$ & $-0.00113^{* *}$ & $-0.0011^{*}$ & $-0.0013^{* *}$ & -0.0005 \\
\hline Pvalue test on $H_{0}: \beta_{1}=0$ & 0.035 & 0.07 & 0.011 & 0.21 \\
\hline Long - run coefficient $=\beta_{1} /\left(1-\alpha_{1}-\alpha_{2}\right)$ & -0.011 & -0.009 & -0.011 & -0.005 \\
\hline \multirow[t]{3}{*}{ Nobs } & 362 & 362 & 362 & 362 \\
\hline & \multicolumn{4}{|c|}{ Panel B } \\
\hline & REGOL & REGNO & BEVI & REGPO \\
\hline Model 1 & & & & \\
\hline Sum $=\beta_{0}+\beta_{1}+\beta_{2}$ & $-0.0009^{* *}$ & $-0.0008^{*}$ & $-0.0008^{* *}$ & -0.0004 \\
\hline Pvalue test on $H_{0}:$ Sum $=0$ & 0.04 & 0.10 & 0.04 & 0.16 \\
\hline Long - run coefficient $=\left(\beta_{0}+\beta_{1}+\beta_{2}\right) /\left(1-\alpha_{1}-\alpha_{2}\right)$ & -0.006 & -0.005 & -0.0055 & -0.003 \\
\hline Pvalue test on $H_{0}: \beta_{0}=\beta_{1}=\beta_{2}=0$ & 0.24 & 0.42 & 0.13 & 0.39 \\
\hline Nobs & 578 & 578 & 578 & 578 \\
\hline \multicolumn{5}{|l|}{ Model $2\left(\beta_{0}=0\right)$} \\
\hline$S u m=\beta_{1}+\beta_{2}$ & $-0.0009^{* *}$ & $-0.0008^{*}$ & $-0.0009^{* *}$ & -0.0004 \\
\hline Pvalue test on $H_{0}:$ Sum $=0$ & 0.04 & 0.09 & 0.028 & 0.16 \\
\hline Long - run coefficient $=\left(\beta_{1}+\beta_{2}\right) /\left(1-\alpha_{1}-\alpha_{2}\right)$ & -0.006 & -0.005 & -0.006 & -0.003 \\
\hline Pvalue test on $H_{0}: \beta_{1}=\beta_{2}=0$ & 0.12 & 0.25 & 0.084 & 0.23 \\
\hline Nobs & 578 & 578 & 578 & 578 \\
\hline \multicolumn{5}{|l|}{ Model $3\left(\beta_{0}=\beta_{2}=0\right)$} \\
\hline$\beta_{1}$ & $-0.0008^{*}$ & -0.0007 & $-0.0007^{* *}$ & -0.0003 \\
\hline Pvalue test on $H_{0}: \beta_{1}=0$ & 0.07 & 0.12 & 0.04 & 0.24 \\
\hline Long - run coefficient $=\beta_{1} /\left(1-\alpha_{1}-\alpha_{2}\right)$ & -0.006 & -0.005 & -0.005 & -0.002 \\
\hline Nobs & 600 & 600 & 600 & 600 \\
\hline
\end{tabular}

Notes: Dependent variable $(I / K)_{i j t}$ defined as investment divided by the capital stock of country $i$, sector $j$, year $t$.

Regulation indices used: REGOL, REGNO, BEVI, REGPO.

Country fixed effects, sector fixed effects, sector specific year dummies are included.

Model 1: $(I / K)_{i j t}=\sum_{s=1}^{2} \alpha_{s}(I / K)_{i j t-s}+\sum_{s=0}^{2} \beta_{s} R E G_{i j t-s}+\gamma_{i}+\delta_{j}+\zeta_{j t}+\varepsilon_{i j t}$.

Model 2: $(I / K)_{i j t}=\sum_{s=1}^{2} \alpha_{s}(I / K)_{i j t-s}+\sum_{s=1}^{2} \beta_{s} R E G_{i j t-s}+\gamma_{i}+\delta_{j}+\zeta_{j t}+\varepsilon_{i j t}$.

Model 3: $(I / K)_{i j t}=\sum_{s=1}^{2} \alpha_{s}(I / K)_{i j t-s}+\beta_{1} R E G_{i j t-1}+\gamma_{i}+\delta_{j}+\zeta_{j t}+\varepsilon_{i j t}$.

$R E G$ stands for one of the following: REGOL, REGNO, BEVI, REGPO.

${ }^{* *}$ Sum significant at the $5 \%$ level; ${ }^{*}$ Sum significant at the $10 \%$ level. 


\begin{tabular}{|c|c|c|c|c|}
\hline & \multicolumn{4}{|c|}{ Panel B } \\
\hline & REGOL & REGNO & BEVI & REGPO \\
\hline \multicolumn{5}{|l|}{ Model 2} \\
\hline $\operatorname{Sum} 1=\beta_{1}+\beta_{2}$ & $-0.001^{* *}$ & $-0.0007^{*}$ & $-0.0008^{* *}$ & -0.0005 \\
\hline Pvalue test on $H_{0}:$ Sum $1=0$ & 0.025 & 0.076 & 0.032 & 0.118 \\
\hline Long - run coefficient $=\left(\beta_{1}+\beta_{2}\right) /\left(1-\alpha_{1}-\alpha_{2}\right)$ & -0.005 & -0.004 & -0.004 & -0.002 \\
\hline Pvalue test on $H_{0}: \beta_{1}=\beta_{2}=0$ & 0.07 & 0.15 & 0.09 & 0.19 \\
\hline $\operatorname{Sum} 2=\psi_{1}+\psi_{2}$ & $0.039^{* *}$ & $0.038^{* *}$ & $0.037^{* *}$ & $0.04^{* *}$ \\
\hline Pvalue test on $H_{0}:$ Sum $2=0$ & 0.0001 & 0.0001 & 0.0002 & 0.000 \\
\hline Long - run coefficient $=\left(\psi_{1}+\psi_{2}\right) /\left(1-\alpha_{1}-\alpha_{2}\right)$ & 0.19 & 0.19 & 0.19 & 0.21 \\
\hline Pvalue test on $H_{0}: \psi_{1}=\psi_{2}=0$ & 0.0006 & 0.0007 & 0.0008 & 0.0002 \\
\hline Nobs & 578 & 578 & 578 & 578 \\
\hline
\end{tabular}

Notes: Dependent variable $(I / K)_{i j t}$ defined as investment divided by the capital stock of country $i$, sector $j$, year $t$.

Regulation indices used: REGOL, REGNO, BEVI, REGPO.

Country fixed effects, sector fixed effects, and common year dummies are included.

Model 2: $(I / K)_{i j t}=\sum_{s=1}^{2} \alpha_{s}(I / K)_{i j t-s}+\sum_{s=1}^{2} \beta_{s} R E G_{i j t-s}+\sum_{s=1}^{2} \psi_{s}(Y / K)_{i j t-s}+\gamma_{i}+\delta_{j}+\zeta_{t}+\varepsilon_{i j t}$.

$R E G$ stands for one of the following: REGOL, REGNO, BEVI, REGPO. $Y$ stands for value added.

** Sum significant at the $5 \%$ level; ${ }^{*}$ Sum significant at the $10 \%$ level.

Table 4: Regulation and Output

\begin{tabular}{|c|c|c|c|c|}
\hline & \multicolumn{4}{|c|}{ Panel B } \\
\hline Model 2 & REGOL & REGNO & BEVI & REGPO \\
\hline Sum $1=\beta_{1}+\beta_{2}$ & $-0.0008^{*}$ & -0.0006 & -0.0004 & $-0.0006^{*}$ \\
\hline Pvalue test on $H_{0}:$ Sum $1=0$ & 0.06 & 0.16 & 0.25 & 0.07 \\
\hline Long - run coefficient $=\left(\beta_{1}+\beta_{2}\right) /\left(1-\alpha_{1}-\alpha_{2}\right)$ & -0.036 & -0.027 & -0.029 & -0.028 \\
\hline Pvalue test on $H_{0}: \beta_{1}=\beta_{2}=0$ & 0.13 & 0.04 & 0.016 & 0.17 \\
\hline Nobs & 631 & 631 & 631 & 631 \\
\hline
\end{tabular}

Notes: Dependent variable $(Y / K)_{i j t}$ defined as value added divided by the capital stock of country $i$, sector $j$, year $t$.

Regulation indices used: REGOL, REGNO, BEVI, REGPO.

Country fixed effects, sector fixed effects, and common year dummies are included.

Model 2: $(Y / K)_{i j t}=\sum_{s=1}^{2} \alpha_{s}(Y / K)_{i j t-s}+\sum_{s=1}^{2} \beta_{s} R E G_{i j t-s}+\gamma_{i}+\delta_{j}+\zeta_{t}+\varepsilon_{i j t}$.

$R E G$ stands for one of the following: REGOL, REGNO, BEVI, REGPO.

** Sum significant at the $5 \%$ level; * Sum significant at the $10 \%$ level. 
Table 5: Regulation and Investment: Heterogeneity Across Countries and Sectors

\begin{tabular}{c|cccc}
\hline \hline Part I & \multicolumn{4}{c}{ Panel B } \\
\hline Model 2 & REGOL & REGNO & BEVI & REGPO \\
$\lambda_{2}$ & & & & \\
& $-0.0012^{* *}$ & $-0.0012^{* *}$ & $-0.0012^{* *}$ & -0.0005 \\
$\vartheta_{2}$ & $(-2.78)$ & $(-2.93)$ & $(-3.20)$ & $(-1.62)$ \\
& $-0.171^{* *}$ & $-0.17^{* *}$ & $-0.171^{* *}$ & $-0.172^{* *}$ \\
Long - run coefficient $=-\left(\lambda_{2} / \vartheta_{2}\right)$ & $(-7.39)$ & $(-7.38)$ & $(-7.45)$ & $(-7.69)$ \\
Nobs & -0.007 & -0.007 & -0.007 & -0.003 \\
& 578 & 578 & 578 & 578 \\
\hline Part II & & & & \\
\hline \multirow{2}{*}{ Model 2} & & & Panel B & \\
$\lambda_{2}$ & REGOL & REGNO & BEVI & REGPO \\
$\vartheta_{2}$ & $-0.0012^{* *}$ & $-0.0010^{* *}$ & $-0.0009^{* *}$ & $-0.0005^{*}$ \\
& $(-2.80)$ & $-2.41)$ & $(-2.58)$ & $(-1.78)$ \\
\hline Long - run coefficient $=-\left(\lambda_{2} / \vartheta_{2}\right)$ & $-0.155^{* *}$ & $-0.153^{* *}$ & $-0.153^{* *}$ & $-0.149^{* *}$ \\
Nobs & $-(-6.87)$ & $(-6.78)$ & $(-6.77)$ & $(-6.74)$ \\
& -0.007 & -0.007 & -0.006 & -0.003 \\
\hline \hline
\end{tabular}

Notes: Estimation of Model 2 reparametrized as follows:

$\Delta(I / K)_{i j t}=\vartheta_{1} \Delta(I / K)_{i j t-1}+\lambda_{1} \Delta R E G_{i j t-1}+\vartheta_{2}(I / K)_{i j t-2}+\lambda_{2} R E G_{i j t-2}+\gamma_{i}+\delta_{j}+\zeta_{t}+\varepsilon_{i j t}$.

$(I / K)_{i j t}$ defined as investment divided by the capital stock of country $i$, sector $j$, year $t$.

$R E G$ stands for one of the following: REGOL, REGNO, BEVI, REGPO.

$\vartheta_{1}, \lambda_{1}$ differ across countries in Part I and across sectors in Part II.

Country fixed effects, sector fixed effects, and common year dummies are included.

t-statistics in parenthesis. ${ }^{* *}$ coefficients significant at the $5 \%$ level; ${ }^{*}$ coefficients significant at the $10 \%$ level. 
Table 6: Regulation and Investment: Nonlinearities

\begin{tabular}{|c|c|c|c|c|}
\hline Part I: Level and Square of Regulation & \multicolumn{4}{|c|}{ Panel B } \\
\hline \multirow{3}{*}{$\begin{array}{c}\text { Model } 2 \\
R E G\end{array}$} & REGOL & REGNO & BEVI & REGPO \\
\hline & & & & \\
\hline & $\begin{array}{c}-0.0048^{* *} \\
(-2.50)\end{array}$ & $\begin{array}{c}-0.0046^{* *} \\
(-2.45)\end{array}$ & $\begin{array}{c}-0.0045^{* *} \\
(-2.97)\end{array}$ & $\begin{array}{l}-0.002 \\
(-1.39)\end{array}$ \\
\hline \multirow[t]{2}{*}{$R E G^{2}$} & $0.0004^{*}$ & $0.0004^{*}$ & $0.0004^{*}$ & 0.0002 \\
\hline & $(1.89)$ & $(1.92)$ & $(2.33)$ & $(1.03)$ \\
\hline \multirow[t]{2}{*}{$\vartheta_{2}$} & $-0.171^{* *}$ & $-0.166^{* *}$ & $-0.165^{* *}$ & $-0.156^{* *}$ \\
\hline & $(-7.32)$ & $(-7.19)$ & $(-7.25)$ & $(-6.82)$ \\
\hline Nobs & 578 & 578 & 578 & 578 \\
\hline Part II: Size of Change in Regulation & \multicolumn{4}{|c|}{ Panel B } \\
\hline & REGOL & REGNO & BEVI & REGPO \\
\hline Model 2 & & & & \\
\hline$R E G * L A R G E$ & $-0.0014^{* *}$ & $-0.0011^{* *}$ & $-0.0011^{* *}$ & $-0.0006^{*}$ \\
\hline$R E G * S M A L L$ & $-0.0011^{* *}$ & $-0.001^{* *}$ & $-0.0007^{*}$ & -0.00003 \\
\hline & $(-2.48)$ & $(-2.33)$ & $(-1.83)$ & $(-0.09)$ \\
\hline \multirow[t]{2}{*}{$\vartheta_{2}$} & $-0.171^{* *}$ & $-0.159^{* *}$ & $-0.169^{* *}$ & $-0.165^{* *}$ \\
\hline & $(-7.27)$ & $(-6.94)$ & $(-7.24)$ & $(-7.15)$ \\
\hline Pvalue test on $H_{0}: \lambda_{2}^{L}=\lambda_{2}^{S}$ & 0.09 & 0.71 & 0.07 & 0.02 \\
\hline Nobs & 578 & 578 & 578 & 578 \\
\hline Part III: Timing of Changes in Regulation & \multicolumn{4}{|c|}{ Panel B } \\
\hline \multirow{2}{*}{$\begin{array}{c}\text { Model } 2 \\
R E G * L A T\end{array}$} & REGOL & REGNO & BEVI & REGPO \\
\hline & $\begin{array}{c}-0.0007 \\
(-0.12)\end{array}$ & $\begin{array}{c}-0.0004 \\
(-0.83)\end{array}$ & $\begin{array}{c}-0.0004 \\
(-0.81)\end{array}$ & $\begin{array}{c}-0.0004 \\
(-1.18)\end{array}$ \\
\hline$R E G * E A R L Y$ & $\begin{array}{c}-0.0023^{* *} \\
(-4.35)\end{array}$ & $\begin{array}{c}-0.0018^{* *} \\
(-3.69)\end{array}$ & $\begin{array}{c}-0.0018^{* *} \\
(-4.17)\end{array}$ & $\begin{array}{c}-0.0013^{* *} \\
(-2.79)\end{array}$ \\
\hline$\vartheta_{2}$ & $\begin{array}{c}-0.189^{* *} \\
(-7.91)\end{array}$ & $\begin{array}{c}-0.176^{* *} \\
(-7.46)\end{array}$ & $\begin{array}{c}-0.181^{* *} \\
(-7.63)\end{array}$ & $\begin{array}{c}-0.182^{* *} \\
(-7.54)\end{array}$ \\
\hline \multirow[t]{2}{*}{$\eta_{0}$} & $-0.009^{* *}$ & $-0.005^{*}$ & $-0.005^{*}$ & -0.001 \\
\hline & $(-2.49)$ & $(-1.91)$ & $(-1.93)$ & $(-0.44)$ \\
\hline Pvalue test on $H_{0}: \lambda_{2}^{L A}=\lambda_{2}^{E A}$ & 0.002 & 0.012 & 0.007 & 0.07 \\
\hline Nobs & 578 & 578 & 578 & 578 \\
\hline
\end{tabular}

Notes: Part I: Model 2 reparametrized as follows: $\Delta(I / K)_{i j t}=\vartheta_{1} \Delta(I / K)_{i j t-1}+\lambda_{1} \Delta R E G_{i j t-1}+$

$+\vartheta_{2}(I / K)_{i j t-2}+\lambda_{2} R E G_{i j t-2}+\lambda_{3} R E G_{i j t-2}^{2}+\gamma_{i}+\delta_{j}+\zeta_{t}+\varepsilon_{i j t}$.

Part II: Model 2 reparametrized as follows: $\Delta(I / K)_{i j t}=\vartheta_{1} \Delta(I / K)_{i j t-1}+\lambda_{1} \Delta R E G_{i j t-1}+$

$+\vartheta_{2}(I / K)_{i j t-2}+\lambda_{2}^{L} R E G_{i j t-2}(L A R G E)+\lambda_{2}^{S} R E G_{i j t-2}(S M A L L)+\gamma_{i}+\delta_{j}+\zeta_{t}+\varepsilon_{i j t}$.

Part III: Model 2 reparametrized as follows: $\Delta(I / K)_{i j t}=\vartheta_{1} \Delta(I / K)_{i j t-1}+\lambda_{1} \Delta R E G_{i j t-1}+$

$+\vartheta_{2}(I / K)_{i j t-2}+\lambda_{2}^{L A} R E G_{i j t-2}(L A T E)+\lambda_{2}^{E A} R E G_{i j t-2}(E A R L Y)+\eta_{0} L A T E+\gamma_{i}+\delta_{j}+\zeta_{t}+\varepsilon_{i j t}$

$(I / K)_{i j t}$ defined as investment divided by the capital stock of country $i$, sector $j$, year $t$.

$R E G$ stands for one of the following: REGOL, REGNO, BEVI, REGPO.

$L A R G E(S M A L L)$ is equal to one if the change in the regulation index between 1975 and 1998 is

bigger (smaller) than the median change in the sample and zero otherwise.

$L A T E(E A R L Y)$ is a dummy variable equal to one if the regulation index begun decreasing

before (after) 1990 zero otherwise.

Country fixed effects, sector fixed effects, and common year dummies are included.

t-statistics in parenthesis. ${ }^{* *}$ coefficients significant at the $5 \%$ level; ${ }^{*}$ coefficients significant at the $10 \%$ level. 


\section{Figure 1: Regulation 1975 - 1998}

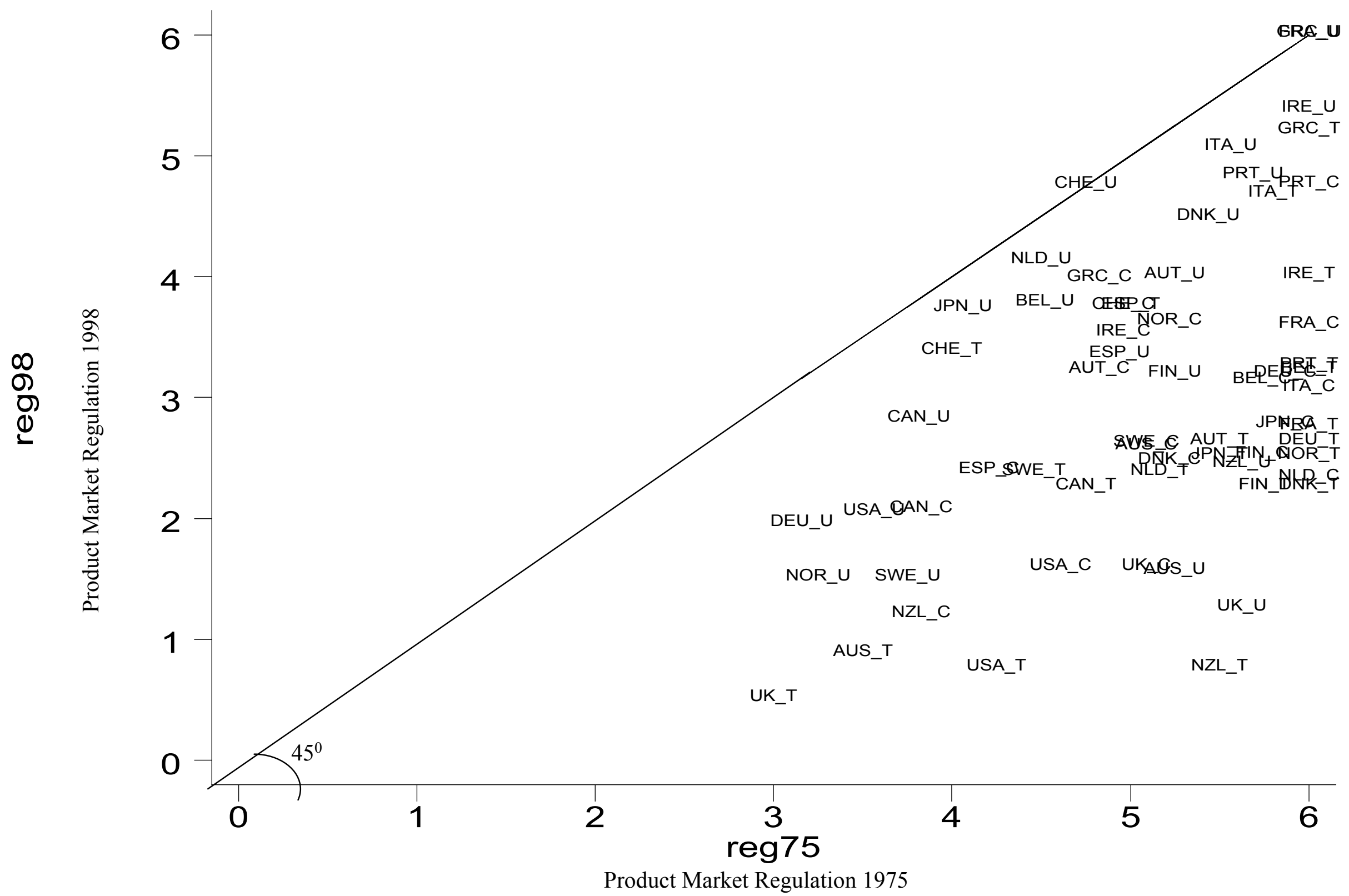


Figure 2: Entry barriers in selected countries, 1975 - 1998

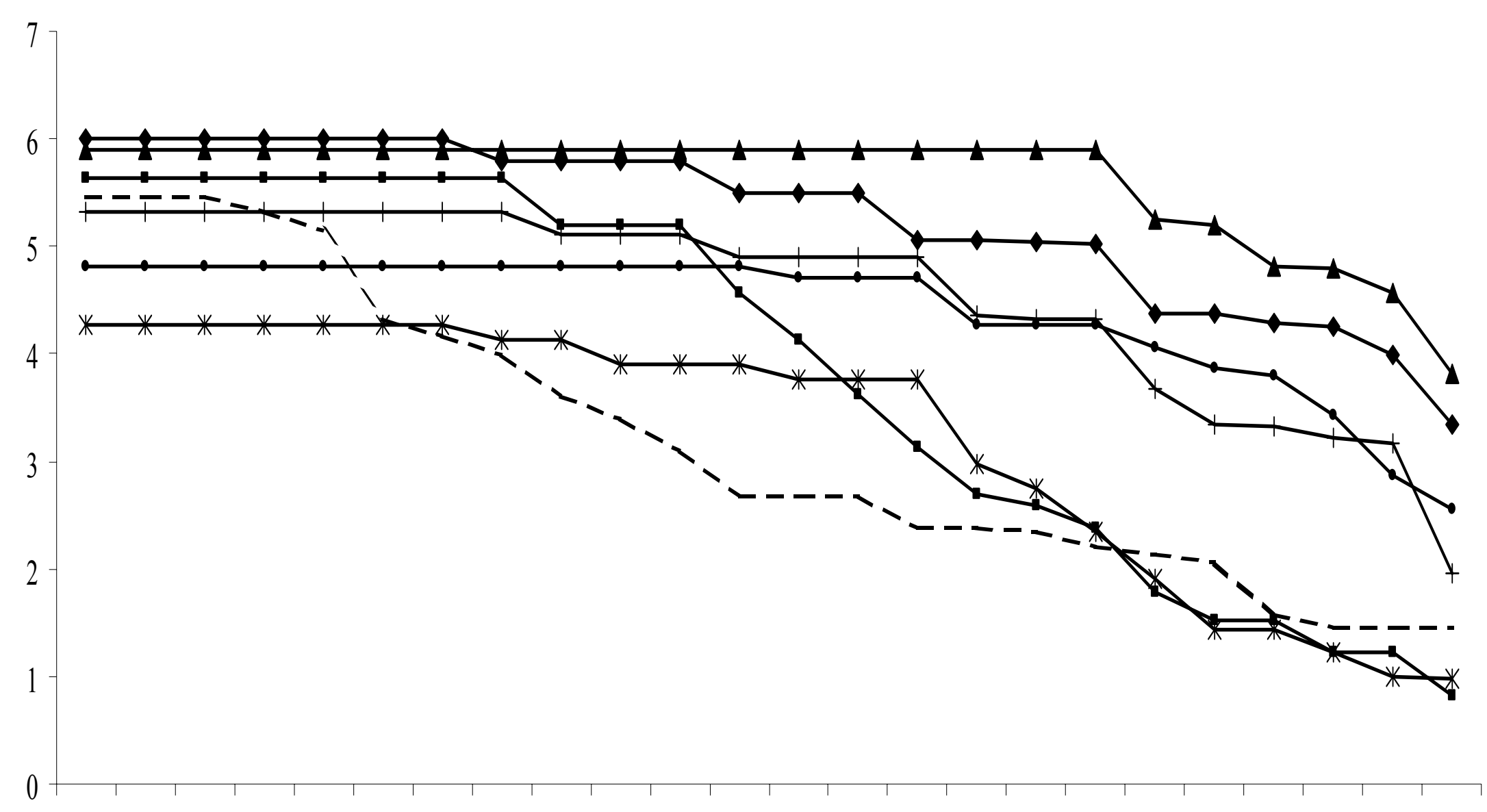

197519761977197819791980198119821983198419851986198719881989199019911992199319941995199619971998

$$
\multimap \mathrm{FRA} \longrightarrow \mathrm{DEU} \rightarrow \mathrm{ITA} \rightarrow \mathrm{NZL} \rightarrow \mathrm{UK}--\mathrm{USA} \rightarrow \mathrm{ESP}
$$


Figure 3: Public ownership in selected countries, 1975 - 1998

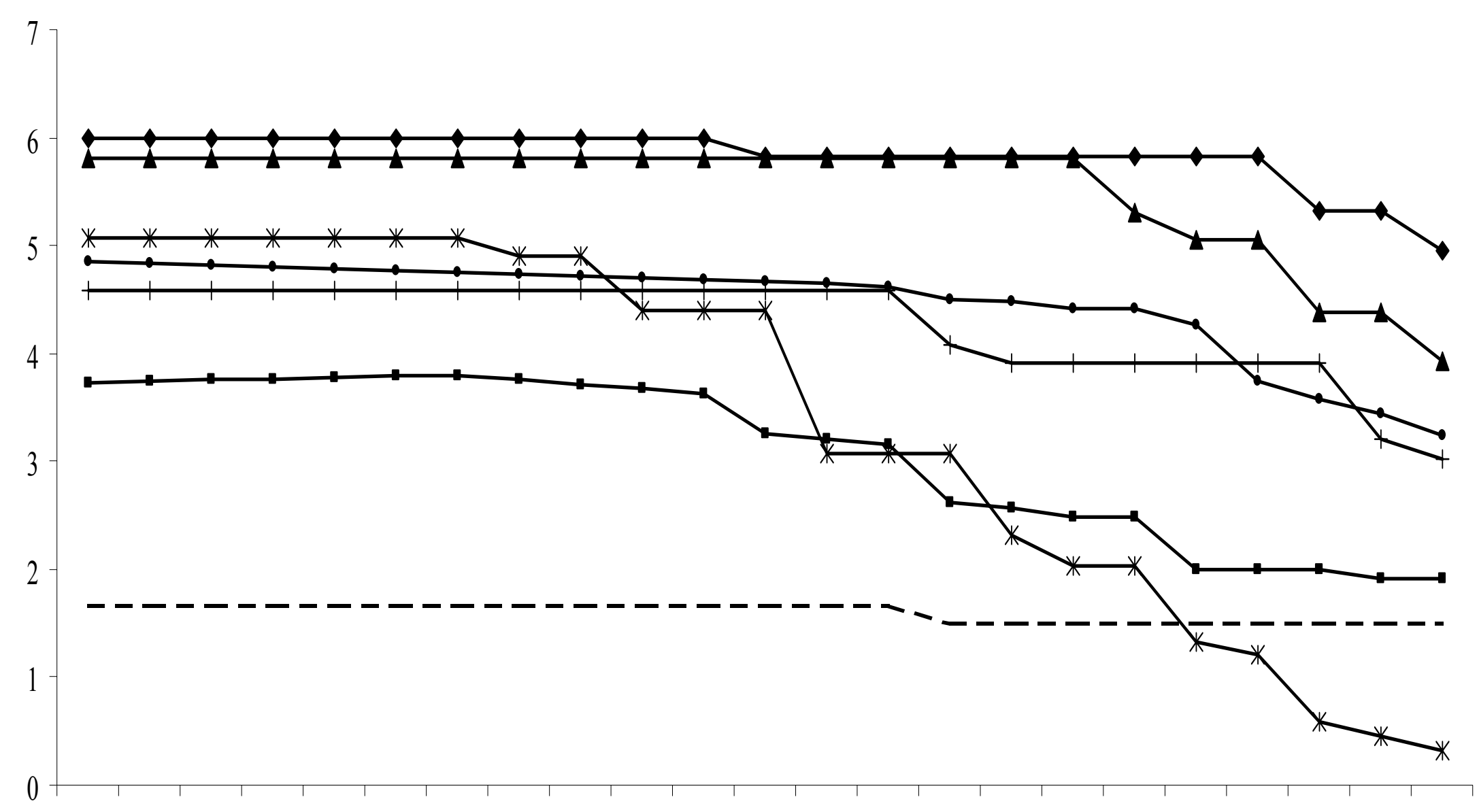

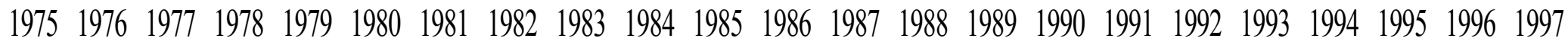

$$
\rightarrow \mathrm{FRA} \longrightarrow \mathrm{DEU} \rightarrow \mathrm{ITA} \rightarrow \mathrm{NZL} \rightarrow \mathrm{UK}--\mathrm{USA} \rightarrow-\mathrm{ESP}
$$




\section{Figure 4: Investment in selected countries, 1975 - 1998}

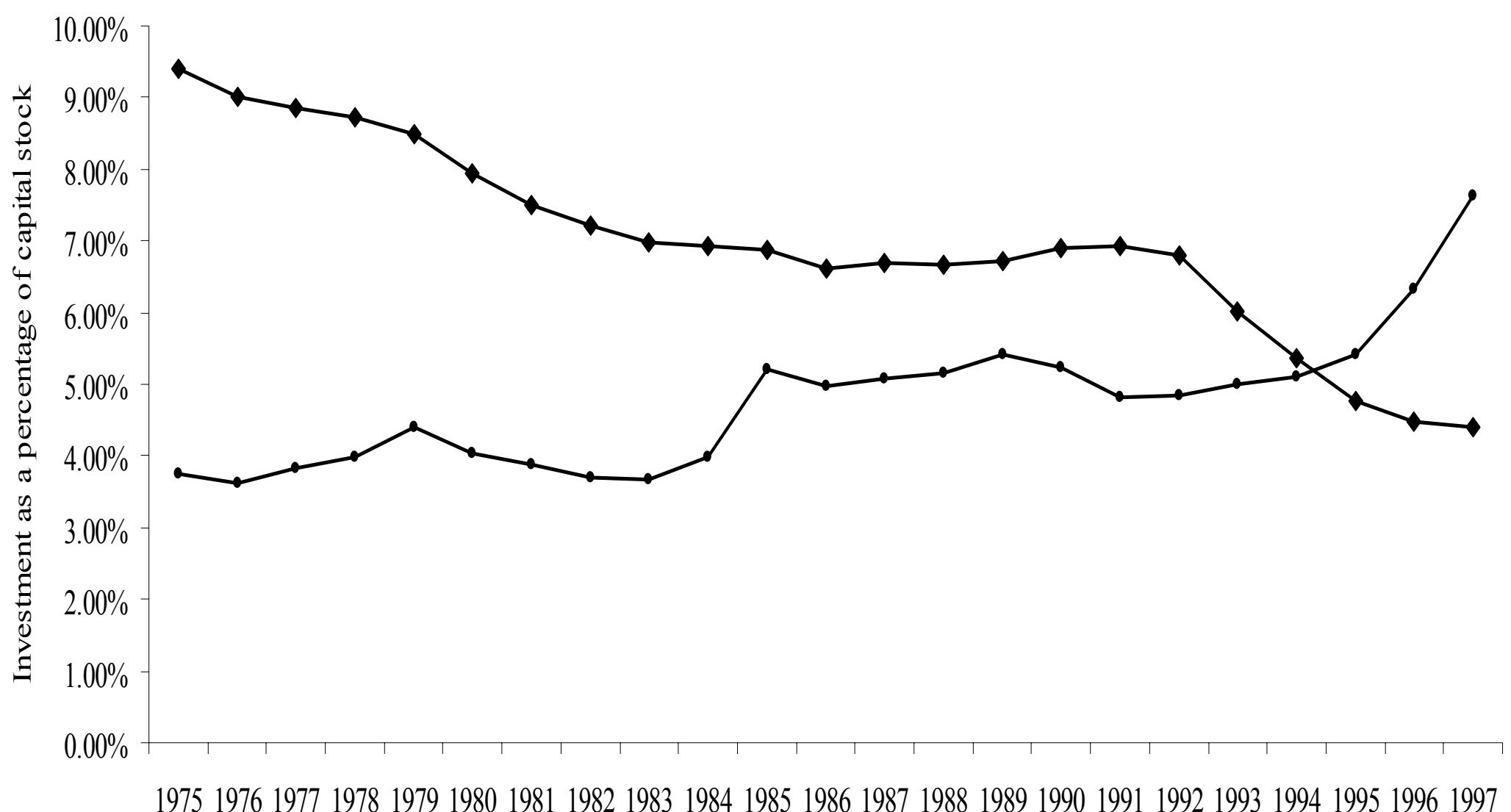

$\rightarrow$ FRA, ITA, DEU $\rightarrow$ UK, USA 